\title{
Detecting Ocean Eddies Automatically from MODIS L1B Data
}

\author{
Jian DING ${ }^{1}$ and Shuang-Shang ZHANG ${ }^{2, a,{ }^{*}}$ \\ ${ }^{1}$ College of Coastal, Harbor and Offshore Engineering, Hohai University, Nanjing, China \\ ${ }^{2}$ College of Oceanography, Hohai University, Nanjing, China \\ aEmail: ang104@yeah.net \\ ${ }^{*}$ Corresponding author
}

Keywords: MODIS, ocean eddy.

\begin{abstract}
This study aims at the automatic detection of the ocean eddies from Moderate Resolution Imaging Spectrometer (MODIS) L1B data in the China Seas. First, the sea surface temperature (SST) is estimated from MODIS Aqua/Terra L1B data using the nonlinear IMAPP algorithm. Based on the distribution of SST, the characteristics of ocean eddies such as the position, the size, and the elliptical parameters can be investigated using the multi-scale edge detection technique. The MODIS L1B data can be obtained in near real time, therefore, the automatic near-real-time detection of ocean eddies can be realized.
\end{abstract}

\section{Introduction}

Ocean eddies play a significant role in determining the overall circulation of the world oceans and are intimately related to the transport of heat, vorticity, momentum and biological tracers. This important process is difficult to study because of the scarcity of in situ observations. With the development of remote sensing technology, the high-resolution remote sensing data with a large spatial coverage have greatly improved our ability to study the characteristics of this oceanic process [1].

Since ocean eddies are related to the Sea Surface Temperature (SST), they can be effectively detected by using SST. Several research works have used SST estimated from satellite infrared images to detect eddies because of the surface signature of the eddy in temperature [2, 3]. However, few studies focus on the eddy detection directly from the visible/infrared data which are used to generate SST images. Usually the SST products can not be provided in real time or near-real time. In contrast, the infrared images from some satellites, such as the Earth Observing System (EOS) Moderate Resolution Imaging Spectrometer (MODIS) Level 1B (L1B) data, can be obtained in real/near-real time. Such data have a higher resolution than the online SST products derived from them. If these data were applied to identifying ocean eddies, the real/near-real-time eddy detection could be realized. In this study, we aim at detecting the ocean eddies automatically and directly from MODIS L1B data based on the SST distribution derived from them.

\section{Data}

The MODIS L1B data set contains calibrated and geolocated radiances for all 36 MODIS bands and reflectance for the reflective solar bands (Bands 1 through 19 and 26). Two bands are imaged at a resolution of $250 \mathrm{~m}$ at nadir, with five bands at $500 \mathrm{~m}$; the resolution of the remaining 29 bands is 1 $\mathrm{km}$. In this study, L1B data with spatial resolution of $1 \mathrm{~km} \times 1 \mathrm{~km}$ are used to estimate SST [4] based on which the ocean eddies are detected.

\section{Methodology}

For the ocean eddies, the distribution of SST have its unique characteristic. Therefore, to detect this process from MODIS L1B data, we first estimate SST from these data. 


\section{SST Retrieval Method}

Before SST retrieval, the cloud detection is necessary in the processing of infrared/visible satellite remote sensing data. In recent years, a variety of methods have been developed to detect cloud from these data [5, 6]. By analyzing the atmospheric radiation characteristics of cloud at different bands and integrating the spectral characteristics of MODIS data, [7] developed a cloud detection algorithm based on multi-spectrum synthesis. Taking into account the factors such as the reflectance within visible bands, the brightness temperature (BT) and BT difference within infrared bands, the cloud mask which discriminates cloud from clear sky can be built. This cloud detection algorithm was proved to be effective, especially for thin cirrus which can not be identified within the visible bands, and is applied in this study.

A comparison of Multi-Channel SST (MCSST) [8], Nonlinear SST (NLSST) [9], Water Vapor SST (WVSST) and Quadratic SST (QDSST) [10] algorithms which retrieve SST from MODIS L1B data showed that the NLSST method has both quality and high efficiency in the Western North Pacific [4]. Thus, the NLSST algorithm is used in our study for estimating SST in the China Seas.

The NLSST is given as,

$$
T_{s}=k_{0}+k_{1} T_{1}+k_{2}\left(T_{1}-T_{2}\right) T_{e n v}+k_{3}(1 / \mu-1),
$$

Where $T_{e n v}$ is an environment temperature; $\mu$ is the cosine of the viewing zenith angle; $k_{0} \sim k_{3}$ are platform (Terra or Aqua) dependent coefficients. Specifically, in the IMAPP (International MODIS AIRS Processing Package) algorithm, the NLSST is (Davie, 2004)

$$
\begin{aligned}
& \text { sst }=k_{0}+k_{1} T_{31}+k_{2}\left\langle T_{31}-T_{32}\right\rangle T_{e n v}+k_{3}\left\langle T_{31}-T_{32}\right\rangle(1 / \mu-1) \\
& \text { sst } 4=k_{0}+k_{1} T_{22}+k_{2}\left(T_{22}-T_{23}\right)+k_{3}(1 / \mu-1)
\end{aligned},
$$

where sst is the SST from MODIS bands 31 and 32 (i.e. the $11 / 12 \mu \mathrm{m}$ split window) and sst 4 is the SST from MODIS bands 22 and 23 (i.e. the 3.9/4.1 $\mu \mathrm{m}$ split window) which is only reliable at night; $T_{i}$ are BTs (in Celsius) at the ith MODIS band; $\left\langle T_{31}-T_{32}\right\rangle$ is an ensemble average within a single scan-line; the environment temperature $T_{e n v}$ is sst4 for night-time observations or, for day-time observations, the weekly OISST (Reynolds optimally interpolated SST). In the absence of OISST data, $T_{20}$ is used to estimate $T_{e n v}$. In this way, the IMAPP algorithm uses OISST if available (for $T_{e n v}$ ), but otherwise requires no ancillary data inputs. In this study, considering the SST estimation in near real time, we mainly use $T_{20}$ to estimate $T_{e n v}$.

\section{Detection of Ocean Eddies}

The current studies on ocean eddies, which mainly focus on water mass current analysis and numerical simulation approaches, have been proved to be successful by various applications in different regions. However, with the blowup of multi-source and large-coverage remote sensing data, there are still many difficulties in fast and automatic extraction of spatial information of eddies. Based on the SST map derived from MODIS L1B data, the characteristics of eddies can be studied using different techniques $[11,12]$. In this study, the multi-scale edge detection technique [13] was used.

All the above data processing procedures, the algorithms and the mapping codes are integrated into a package so that either the SST or the detection results can be obtained once the MODIS L1B data are input into the package. In this way, the automatic detection of ocean eddies can be realized.

\section{Results and Discussion}

To show the capability of our system in automatically detecting ocean eddies from MODIS L1B data, case studies are carried out in the China Seas and the Western Pacific. 


\section{SST}

In this study, the SST distribution from MODIS L1B data is the basis for detecting the eddies. Figure 1a shows MODIS Aqua L1B image acquired at 04:15 UTC on 29 April, 2009 in the China Seas and part of Western Pacific. After cloud detection, the SST was estimated using the IMAPP algorithm (Figure 1b). Figure 2 shows the near-real-time SST product generated by the Japan Aerospace Exploration Agency (JAXA) at the same time and in the same region for Figure 1a. The comparison shows that there is a good agreement between the SST derived in our study and the operational SST product from JAXA. This lays the foundation for the following detection of ocean eddies from the MODIS derived SST image.

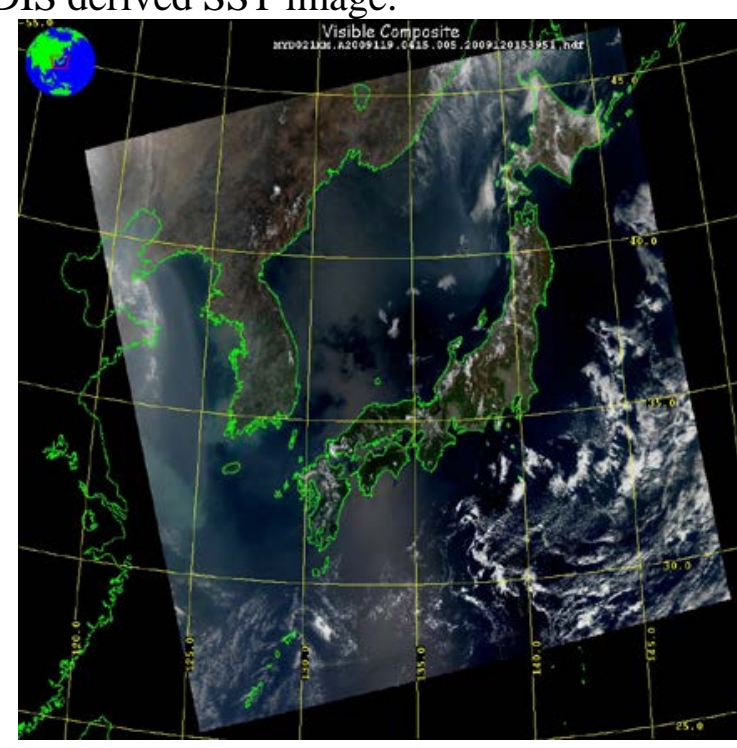

(a)

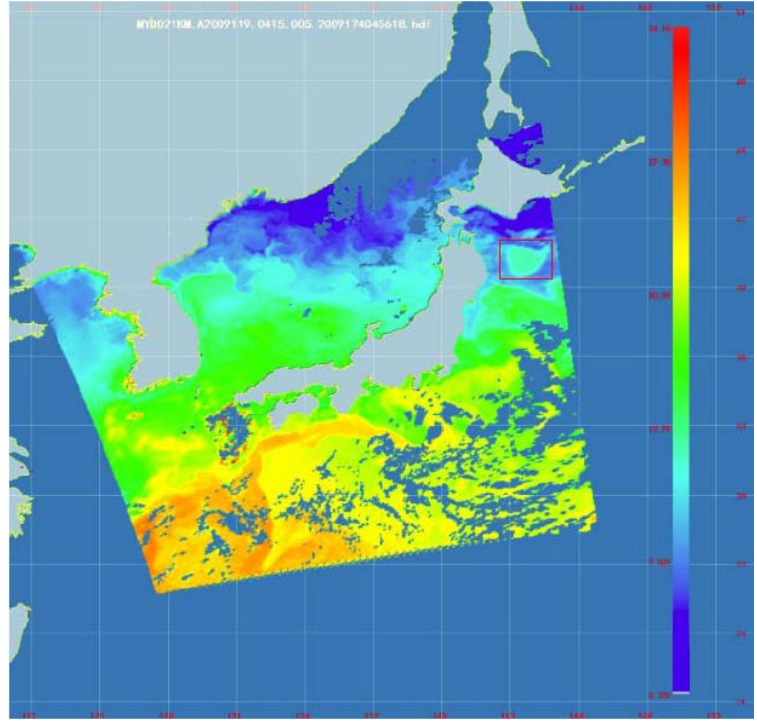

(b)

Fig. 1 (a) MODIS Aqua L1B image acquired at 04:15 UTC on 29 April, 2009. (b) SST estimated from (a) using the IMAPP algorithm

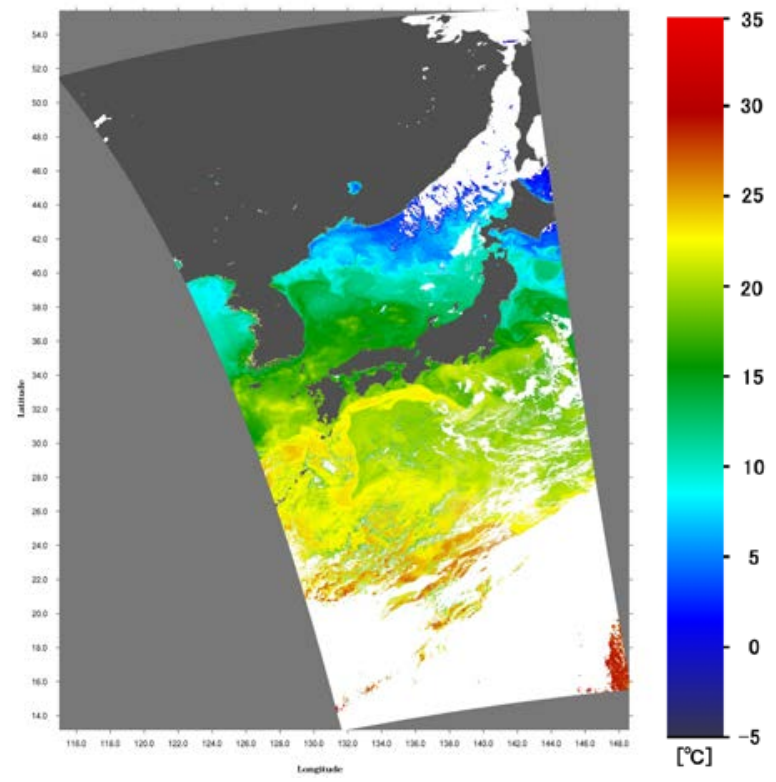

Fig. 2 The SST product generated by the JAXA for Figure 1a. (http://kuroshio.eorc.jaxa.jp/ADEOS/mod_nrt/index.html) 


\section{Ocean Eddy Detection}

Using the detection algorithms, the ocean eddies are automatically detected based on the SST map derived from MODIS L1B data.

Figure 3a is the enlarged image of the SST sub-image marked as the red square in Figure 1b. From Figure 3a we can clearly see an anticyclonic eddy. The information of this eddy is shown in Figure 4b, where the shape of the eddy is successfully extracted. The position of the eddy center is $\left(143.61^{\circ} \mathrm{E}\right.$, $40.15^{\circ} \mathrm{N}$ ). The lengths of major and minor axes of the eddy ellipse are 89.1 and $51.4 \mathrm{~km}$, respectively. Judging from the SST within the eddy and background temperature, we know that this is a warm eddy.

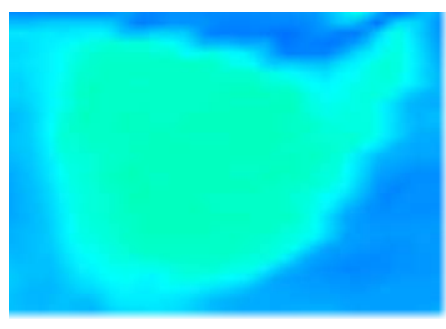

(a)

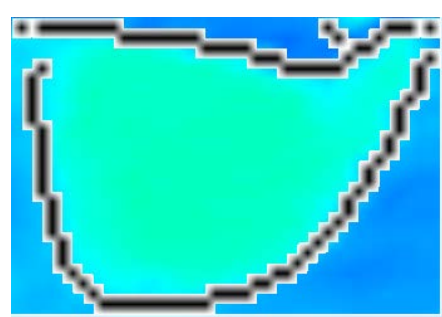

(b)

Fig. 3 Ocean eddy detected from MODIS L1B data. (a) Enlarged image of the sub-image marked as the red square in Figure 1b. (b) Information of the anticyclonic eddy derived from Figure 3a.

Another case is shown in Figure 4 for MODIS Terra L1B data acquired at 01:15 UTC on 11 December, 2008 (not shown) in the Northwestern Pacific. Figure 5a shows SST derived by the IMAPP algorithm. Figures $4 \mathrm{~b}$ and $4 \mathrm{c}$ are the enlarged image of the sub-image marked as the red square in Figure 5a and the shape of the detected cyclonic (cold) eddy. The position of the cold eddy center is $\left(143.96^{\circ} \mathrm{E}, 32.989^{\circ} \mathrm{N}\right)$, with the lengths of major and minor axes of the eddy ellipse as 108.9 and $55.4 \mathrm{~km}$, respectively.

Due to the limitation of the edge detection technique used in this study, the boundaries between SST and non-SST regions are also shown in Fig. 4c. In the further study we will apply improved techniques to automatically remove the boundary lines.

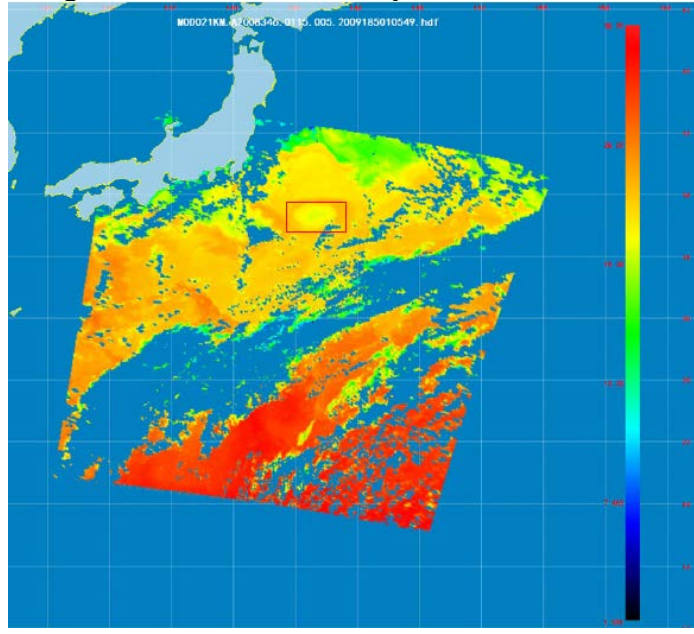

(a)

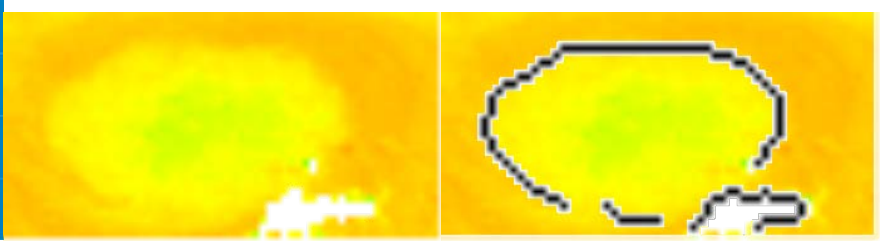

(b) (c)

Fig. 4 Ocean eddy detected from MODIS L1B data. (a) SST derived from MODIS Terra L1B data acquired at 01:15 UTC on 11 December, 2008. (b) Enlarged image of the sub-image marked as the red square in Fig. 5a. (c) Information of the cyclonic eddy. 


\section{Conclusions}

In this paper, the ocean eddies are detected automatically from MODIS (Aqua/Terra) L1B data using an automatic detection system. The detection process is carried out based on the SST retrieved from the L1B data using the nonlinear IMAPP algorithm. Using the detection algorithm, the characteristics of the eddies such as the position, the size, the scale, and the elliptical parameters can be automatically extracted based on the spatial distribution of SST. The MODIS L1B data can be obtained in near real time, therefore, the near-real-time automatic detection of ocean eddies can also be realized. However, a weakness of the system is that it only works under cloud-free condition, which is due to the limitation of visible/infrared remote sensing.

\section{References}

[1] E.D. Conway, the Maryland Space Grant Consortium, an Introduction to Satellite Image Interpretation, Johns Hopkins University Press, Baltimore. (1997) 264 pp.

[2] M. Castellani, Identification of eddies from sea surface temperature maps with neural networks, International Journal of Remote Sensing. 27(8) (2006) 1601 - 1618.

[3] H. Jin, X. Yang, J. Gong, and Z. Gao, Automatic eddy extraction from SST imagery using artificial neural network, Proceedings of ISPRS Congress. XXXVII: (2008) 279-282, Beijing.

[4] K. Hosoda, H. Murakami, F. Sakaida, and H. Kawamura, Algorithm and validation of sea surface temperature using MODIS sensors aboard Terra and Aqua in the Western North Pacific, Journal of Oceanography. 63 (2007) 267-280.

[5] O. Karner, L. Digrolamo, on automatic cloud detection over ocean, International Journal of Remote Sensing. 22(15) (2001) 3047-3052.

[6] K.T. Kriebel, G. Gesell, M. Kastner, and H. Mannstein, The cloud analysis tool APOLLO: improvements and validations, International Journal of Remote Sensing. 24 (12) (2003) 2389-2408.

[7] Q.J. He, J. Cao, J. Huang, Z. Wu, Cloud detection in MODIS data based on multi-spectrum synthesis, Remote Sensing for Land and Resource. 3(69) (2006) 20-22.

[8]E.P. McClain, W.P. Pichel, C.C. Walton, Comparative performance of AVHRR-based multichannel sea surface temperatures, Journal of Geophysical Research. 90 (1985) 11,587-11,601.

[9] C.C. Walton, W.G. Pichel, J.F. Sapper, The development and operational application of nonlinear algorithms for the measurements of sea surface temperatures with the NOAA polar-orbiting environmental satellites, Journal of Geophysical Research. 103 (1998) 27999-28012.

[10] W.J. Emery, Y. Yu, G.A. Wick, P. Schluessel, and R.W. Reynolds, Correcting infrared satellite estimates of sea surface temperature for atmospheric water vapor attenuation, Journal of Geophysical Research. 99 (1994) 5219-5236.

[11] D.G. Nichol, Autonomous extraction of an eddy-like structure from infrared images of the ocean, IEEE Trans. on Geoscience and Remote Sensing. 25 (1) (1987) 28-34.

[12] S.H. Peckinpaugh, R.J. Holyer, Circle detection for extracting eddy size and position from satellite imagery of the ocean, IEEE Trans. on Geoscience and Remote Sensing. 32(2) (1994) 267-273.

[13] G. Ji, X. Chen, Y. Huo, and T. Jia, An automatic detecting method of the marine meso-scale eddy in remote sensing image, Oceanolgica ET Limnologia Sinica (in Chinese). 33(2) (2002) 139-144. 